\title{
Evolutionary Perspective on Microglial/Neuronal Coupling with Special Relevance to Psychiatric Illnesses
}

\section{George B Stefano* and Richard M Kream}

MitoGenetics Research Institute, 3 Bioscience Park Drive, Suite 307, Farmingdale, NY 11735, USA

\begin{abstract}
Microglia have selectively evolved as a morphologically and chemically distinct class of immuno-competent CNS resident cells with potent bidirectional signaling capabilities linked to induction of a macrophage-like phenotype following metabolic, microbiological, or viral insults. It has been empirically determined that a conserved set of shared chemical messengers connects a communication network mediating reciprocal exchange of regulatory information between immune, central nervous, and neuroendocrine systems. From an evolutionary perspective, the pluripotent neuro-protective capabilities of invertebrate microglia have been extended and amplified in classes of mammalian microglia. The state-dependent plasticity of microglia has provoked considerable empirical investigation into their functional/regulatory roles in mediating innate immune surveillance and neural protection within the CNS Upon pathophysiological dysregulation, aberrant microglial activities may provide significant contributory factors in the etiology and persistence of major neurological, degenerative, and psychiatric disorders. Within this context, invertebrate microglia appear to represent highly appropriate model systems to investigate underlying cellular and molecular mechanisms involved in higher order neuroimmune regulation of multiple CNS activities by mammalian microglia.
\end{abstract}

Keywords: Mitochondria; Microglia; Nitric oxide; Nitrite; Morphine; Hypoxia

\section{Introduction}

Selective evolutionary pressure has provided the CNS with a morphologically and chemically distinct class of immuno-competent "vigilante" cell, microglia, with potent bidirectional signaling capabilities linked to induction of a macrophage-like phenotype [1-3]. Concerted developmental studies have established that adult microglia are derived from primitive myeloid precursors within the embryonic yolk sac that subsequently proliferate into mature microglia and seed the brain during later embryonic and perinatal stages [4-10]. During the postnatal period, mature unstimulated microglia maintain a branched or ramified morphology that is transformed into an activated macrophage-like amoeboid state following microbiological or pathophysiological insults [11-13]. As discussed in depth below, the intrinsic, state-dependent, plasticity of microglia has provoked considerable empirical investigation into their functional/regulatory roles in mediating innate immune surveillance and neural protection within the CNS. When dysregulated, it appears that aberrant microglial activities represent significant contributory factors in the etiology and persistence of major neurological, degenerative, and psychiatric disorders $[11,12,14,15]$.

\section{Common Set of Shared Signal Molecules}

The history of neurobiology has demonstrated the value of the invertebrate nervous system as a model for neural phenomena. The giant squid axon and GABAnergic systems are well known examples $[16,20]$. Since the invertebrate center of our review is the bivalve mollusk Mytilus edulis, the examples of evolutionarily conserved chemical signaling will be restricted to this organism. In this regard, monoaminergic neurotransmission is present in this animal, e.g., dopamine, norepinephrine, serotonin, etc. [21]. Cholinergic processes are also present [22]. These reports also demonstrate, on a pharmacological and biochemical basis, that the corresponding receptors are present as well, along with the intracellular second messenger communication processes [23-26]. Opioid peptides and opiate alkaloids (e.g., enkephalins, morphine) are also present with their respective receptors and biosynthetic pathways [27-31]. From a neuroimmune perspective, the same chemical messengers and their receptors have been found on invertebrate immunocytes, including nitric oxide coupling, allowing neurons to communicate with the immune cells, including microglia [32-42] (Figures 1 and 2). RIA and HPLC studies also identified cytokine messengers in these same tissues, e.g., interleukin-1, -6, -10 and tumor necrosis factor along with their receptors [43-51]. Utilizing more modern technologies, like microarray, we have validated the presence of these signaling systems in invertebrate tissues by examining their gene expression patterns [22-52]. There are many more examples of this phenomenon that, for the sake of the review's focus, we will not mention. Thus, the communication between the same cell and other cell types becomes evident, and clearly demonstrates this phenomenon originated much earlier in evolution than previously thought. Hence, the phenomenon of creating networking/pathways of intra-nervous system communication becomes the new evolutionary development advance. It has been well documented within the biomedical literature that both conservation and enhancement of function of common sets of chemical messenger compounds has been exponentially amplified by positive evolutionary pressure. Accordingly, the elucidation of basic mechanistic information regarding diverse mechanistic roles of common sets of chemical messenger molecules has tremendous predictive value within biomedical model systems. Activated macrophages have been demonstrated to synthesize, enzymatically process, and release a variety of pro-inflammatory cytokines, some of which have been shown to influence monoaminergic neural function [27,53]. For example, administration of interleukin-1 (IL-1) was found to enhance in vivo release of dopamine and its acidic metabolite dihydroxyphenylacetic acid from rat hypothalamus [54]. In vivo observations were confirmed by a complementary in vitro

*Corresponding author: George B Stefano, MitoGenetics Research Institute 3 Bioscience Park Drive, Suite 307, Farmingdale, NY 11735, Tel: 6312273930; E-mail: george.stefano@mitogenetics.com

Received July 31, 2015; Accepted September 21, 2015; Published September 29, 2015

Citation: Stefano GB, Kream RM (2015) Evolutionary Perspective on Microglial/ Neuronal Coupling with Special Relevance to Psychiatric Illnesses. J Psychiatry 18: 329 doi:10.4172/2378-5756.1000329

Copyright: (c) 2015 Stefano GB, et al. This is an open-access article distributed under the terms of the Creative Commons Attribution License, which permits unrestricted use, distribution, and reproduction in any medium, provided the original author and source are credited 
Citation: Stefano GB, Kream RM (2015) Evolutionary Perspective on Microglial/Neuronal Coupling with Special Relevance to Psychiatric Illnesses. J Psychiatry 18: 329 doi:10.4172/2378-5756.1000329
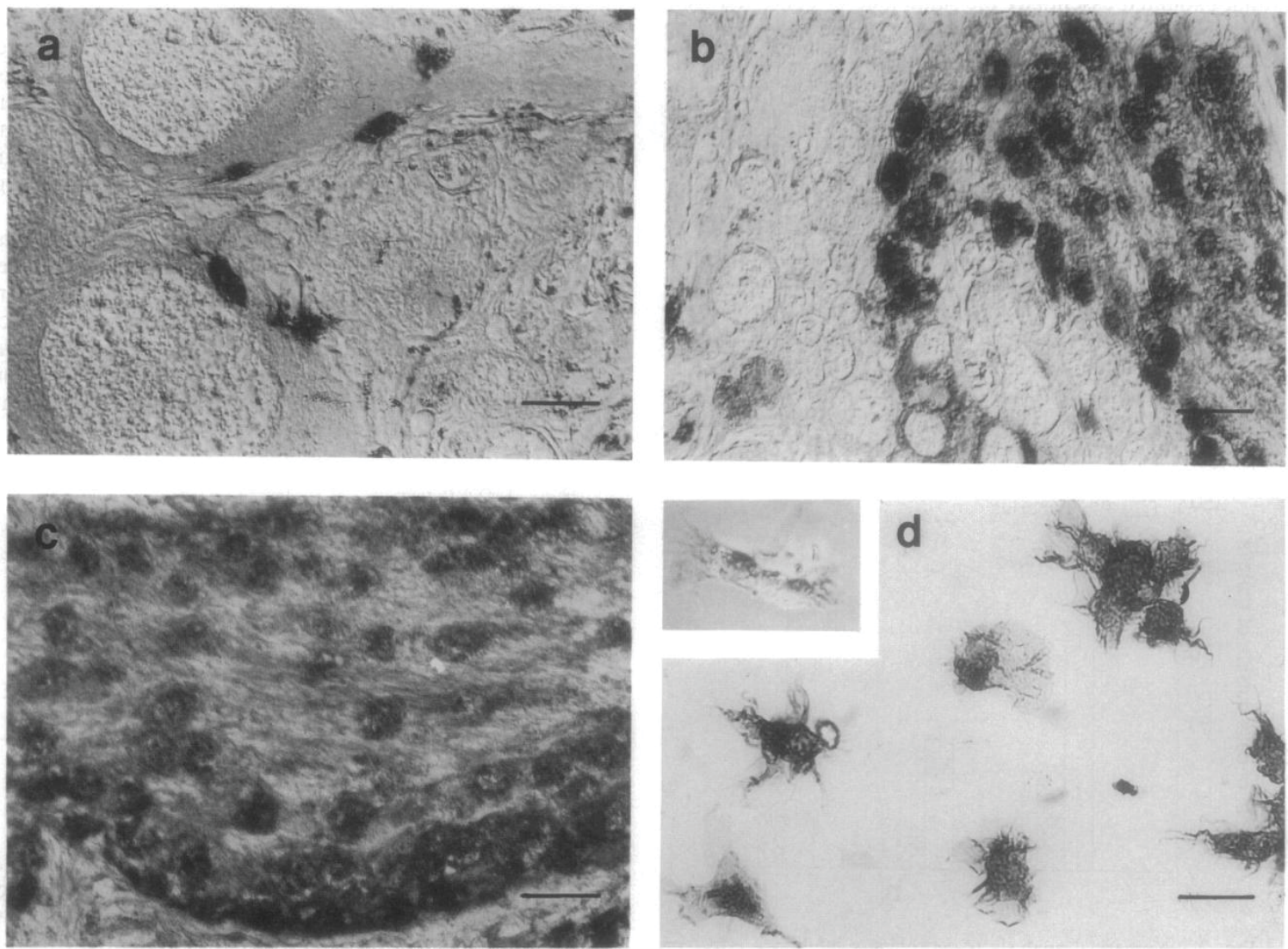

Figure 1: Micrographs of excised visceral ganglia of Planorbarius, demonstrating egress of microglial cells selectively immunostained for the presence of ACTH (Nomarski interference). (a) Microglial cells in close contact with ACTH-negative giant neurons, fixed immediately after excision. (b) Fixed after 24 hr of incubation in culture medium; microglia accumulating in neuropilar region. (c) Accumulation of migrating cells at nerve stump. (d) Ameboid conformation of microglial cells in extraganglionic area. (Inset) Abolition of immunoreaction by omission of the primary antibody. (Bars = 20 um.) From, PNAS, 1994, (62).

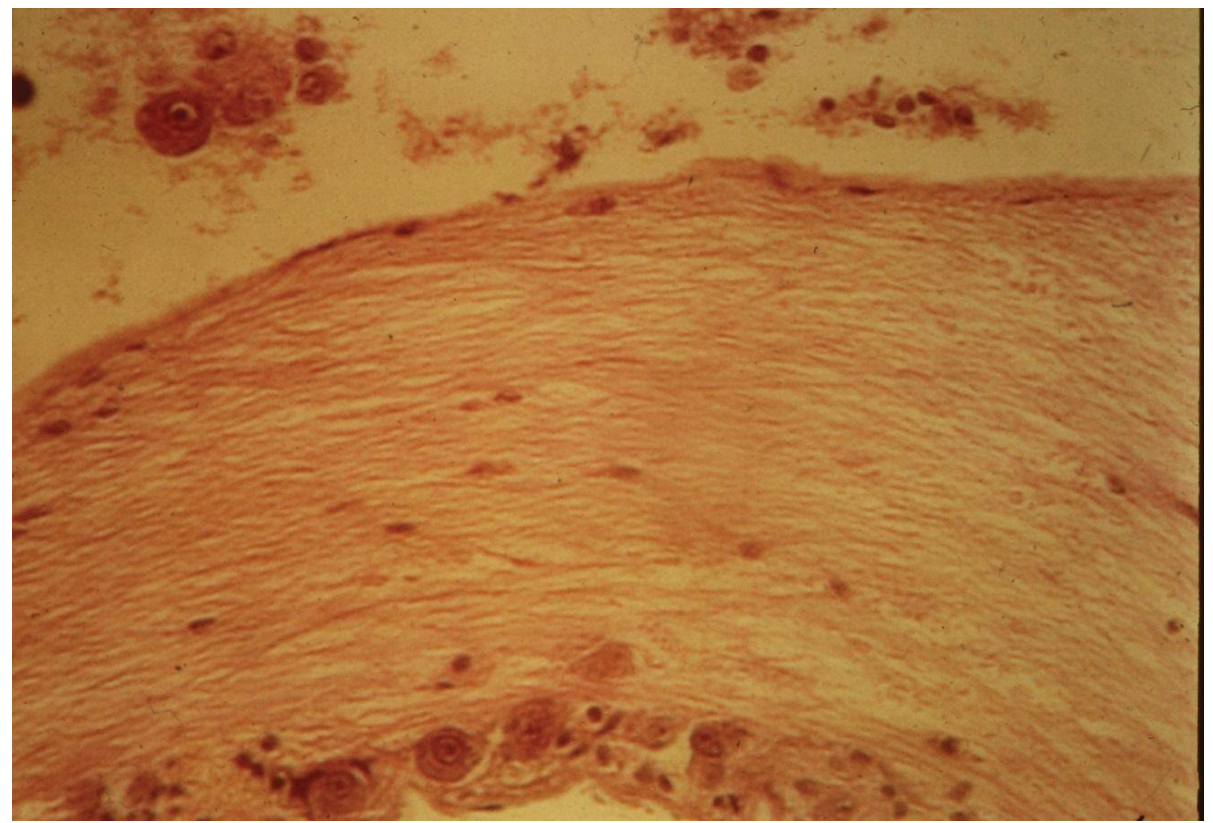

Figure 2: Section of branchial nerve emerging from Mytilus edulis visceral ganglia. Note the macrophage-like cells both free and above the nerve trunk and within it, illustrating their ability to freely penetrate this open nervous system. From Prog. Neurobiology, 1989. 
study demonstrating evoked release of dopamine and norepinephrine from male rat hypothalamic tissues following administration of IL-1b [55]. Accordingly, a major macrophage/microglial secretory product, i.e., IL-1, appears to represent a key regulatory factor underlying neurophysiological functioning of CNS monoaminergic signaling pathways responsible for integration of complex behavioral paradigms. The significance of dysregulated monoaminergic mechanisms in the etiology of major psychiatric illnesses has been documented for the past 40 years, and includes studies on cortically-mediated intractable pain [56-58]. In sum, macrophage/microglial-derived secretory products include molecules capable of selectively altering diverse neuronal activities and must be included in any list of putative etiological factors involved in major psychiatric disorders. Under normative physiological conditions, microglia provide essential surveillance and intra/inter-cellular communication processes subsumed under innate immunological activities. In contrast, an increased number of activated microglia displaying macrophage-like amoeboid morphologies and chemokinetic properties are visualized in affected CNS areas following trauma or physiological stress $[59,60]$. Following excessive chemical or microbiological insults, it is apparent that activated microglia may promote inappropriately deleterious release of signal molecules that can excite, inhibit or damage neurons in their respective vicinity [60]. In sum, aberrant coupling of microglial-neuronal communication may promote severely dysfunctional behavioral consequences often leading to the manifestation of major psychiatric disorders.

\section{Evolutionary Origin of Microglial/Neuronal Coupling}

Throughout invertebrate and mammalian species, the regulatory activities of immuno-competent microglial cells within nervous structures are deemed of critical importance to normative neuronal function. Accordingly, the resident CNS macrophage appears to represent a significant developmental prototype for intercellular mediation of immune-neuro communication processes in animals that evolved at least 500 million years before humans. For example, one of the activities linked to invertebrate glia is functionally associated with the blood-brain barrier integrity of insects, as well as maintenance and repair of invertebrate nerve cells [61]. In earlier reports, invertebrate immuno-competent glial cells have been demonstrated to possess similar properties as previously described for mammalian microglia including a shared set of chemical messengers such as interleukins and opioid peptides [61-64]. These morphological and biochemical similarities suggest an evolutionarily driven functional convergence of immuno-competent glial cells [62-64]. In this regard, our group and others have demonstrated compelling anatomical and biochemical linkages between invertebrate immunocytes/microglia and mammalian monocytic/microglial/macrophage lineages that include functional utilization of a shared set of chemical messengers [27,43,44,51,6567]. Briefly, the listed functional similarities include taken from these reports includes: 1) expression of immunocyte-responsive cytokinelike molecules closely resembling those found in higher animals; 2) cross activation of human immunocytes by invertebrate cytokine-like molecules; 3) initiation of a cytokine-like cascade mechanism induced by lipopolysaccharide (LPS) administration; 4) functional involvement of opioid peptide and opioid receptor mechanisms in cytokine production and release related to manifestation of neural trauma; $5)$ similarities in the metabolic enzyme pathways responsible for the degradation of peptidergic signal molecules; 6) utilization of nitric oxide (NO) as a major regulatory molecule in immunological and neurological tissues $[44,68-70] 7)$ regulated biosynthesis and utilization of endogenous morphine and its stereo-selective mu receptor subtypes as regulatory factors in neural, immune and neuroimmune signaling [45,71-73].

\section{Additional Functional Commonalities}

As described above, the responsiveness of invertebrate and vertebrate immuno-competent microglia to a common set of signal molecules including interleukins, $\mathrm{NO}$, opioid peptides, catecholamines and endogenous morphine is functionally linked to physiologically driven innate immunological activities. As documented by video time lapse microscopy $[62,74]$, this phenomenon is visualized by stationary microglia becoming amoeboid, macrophage-like, and mobile following traumatic stimuli in invertebrate ganglia [62-64,75]. By functional criteria, noted earlier, activated or polarized macrophages represent a potent immune cell type with the potential to secrete numerous neuroactive signal molecules that permit free penetration of the vertebrate the blood-brain barrier. Operationally, macrophages appear to be sentinels of the immune and nervous systems and may exert the same type of surveillance in other systems as well [14]. Invertebrate ganglia contain microglia and macrophage-like cells in their open ganglionic nervous system [33]. Additionally, selected cytokine-like secretory molecules have been observed to evoke neurophysiological changes in invertebrate neurons in a receptor mediated manner [66,76-78]. In sum, the presence of a common set of signal molecules in comparative animal groups, and their innate immunological stimulating activity functionally linked to the induction of significant morphological cellular changes, strongly suggests conservation of this cellular association along with its operational properties.

\section{Retention of Chemical Messengers: Underlying Rationale}

We contend that a likely mechanistic driving force underlying the phenomenon of chemical messenger retention during evolution resides in stereo-selective recognition of enantiomeric compounds within multiple stereo-selective enzyme and receptor signaling pathways [79]. Accordingly, the basic preservation of essential chemical information required for recognition and activation by distinct classes of enzyme and receptors within discrete signaling pathways provides the molecular basis for retention of shared sets of chemical compounds in diverse plant and animal phyla [80,81]. Hence stereo-selective conformational matching in a multiple enzyme or multiple receptor mediated pathway presents a systemic driving force to retain basic chemical identities across animal and plant phyla $[66,79,82-85]$ and in remarkably different cell types. Another common chemical feature of retained signal molecules is the widely expressed precursor to product relationship that allows temporal release of biologically active chemical compounds and peptide sequences from biologically inactive prohormone-like molecules, notably via the action of endo-proteolytic cleavage enzymes $[31,86,87]$. Thus, macrophage secretory products appear to alter well-established monoaminergic signaling pathways responsible for regulating basic physiological functions, as well as integration of complex behavioral paradigms in both vertebrates and invertebrates. The significance of normative and aberrant monoaminergic mechanisms in the etiology of major psychiatric illnesses has been documented and includes studies on corticallymediated intractable pain $[88,89]$. In sum, secretory molecules derived from activated macrophage-like microglia possess potent capabilities for selectively altering a wide variety neuronal activities and must be included in any list of putative etiological factors involved in major 
psychiatric as well as CNS-presenting metabolic disorders [90-93].

\section{Conclusions}

An evolutionary, retroactively-directed, blueprint for elucidation of neural-immune bidirectional communication mechanisms of higher animals may be gleaned from examination of neural and immune processes of invertebrate microglia. Unifying principles responsible for normative bidirectional neural-immune communication across invertebrate and vertebrate species reside in common anatomical and biochemical substrates. The original need for this relationship may reside in the fact that immune and neural cells require a diversity of sensory inputs aimed at survival and longevity regardless of where the respective organism is positioned within the evolutionary tree. Functional maintenance of a shared set of common messenger molecules, as well as other life maintaining chemical processes, resides in an expansive adaptation of stereoselective/conformational matching processes. By evolutionary criteria, the open circulatory system of invertebrates lent itself to the origin of neuroimmune cooperative events, whereby macrophage-like immune cells gained the capabilities for penetration and residence within "privileged" neuronal compartments. Mammalian microglia have evolved as resident immuno-competent guardians against metabolic, microbiological or viral insults to populations of CNS cells via morphological transformation into active macrophages. Adaptation processes underlying exponential expansion of complex cognitive behaviors in higher animals strongly suggest that dysregulation of microglial-direction neuroimmune processes represents a likely contributing factor to the etiology and persistence of major psychiatric disorders afflicting human populations.

\section{References}

1. Perry VH, Hume DA, Gordon S (1985) Immunohistochemical localization of macrophages and microglia in the adult and developing mouse brain Neuroscience 15: 313-326.

2. Perry VH, Gordon S (1991) Macrophages and the nervous system. Int Rev Cytol 125: 203-44.

3. Gordon S (1986) Biology of the macrophage. J Cell Sci Suppl 4: 267-286.

4. 4.Sminia T, de Groot CJ, Dijkstra CD, Koetsier JC, Polman CH (1987) Macrophages in the central nervous system of the rat. Immunobiology 174: 43-50.

5. Alliot F, Godin I, Pessac B (1999) Microglia derive from progenitors, originating from the yolk sac, and which proliferate in the brain. Brain Res Dev Brain Res 117: $145-152$.

6. Ginhoux F, Greter M, Leboeuf M, Nandi S, See P, et al. (2010) Fate mapping analysis reveals that adult microglia derive from primitive macrophages. Science 330: 841-845.

7. Ransohoff RM, Cardona AE (2010) The myeloid cells of the central nervous system parenchyma. Nature 468: 253-62.

8. Prinz M, Mildner A (2011) Microglia in the CNS: immigrants from another world. Glia 59: 177-87.

9. Schlegelmilch T, Henke K, Peri F (2011) Microglia in the developing brain: from immunity to behaviour. Curr Opin Neurobiol 21: 5-10.

10. Kierdorf K, Erny D, Goldmann T, Sander V, Schulz C, et al. (2013) Microglia emerge from erythromyeloid precursors via Pu.1- and Irf8-dependent pathways. Nat Neurosci 16: 273-80

11. Hanisch UK, Kettenmann H (2007) Microglia: active sensor and versatile effector cells in the normal and pathologic brain. Nat Neurosci 10: 1387-1394.

12. Graeber MB, Streit WJ (2010) Microglia: biology and pathology. Acta Neuropathol 119: 89-105.

13. Hristova M, Cuthill D, Zbarsky V, Acosta-Saltos A, Wallace A, et al. (2010) Activation and deactivation of periventricular white matter phagocytes during postnatal mouse development. Glia 58: 11-28.
14. Perry VH (1992) The role of macrophages in models of neurological and psychiatric disorder. PsychMed 22: 551-555.

15. Goldmann T, Tay TL, Prinz M (2013) Love and death: microglia, NLRP3 and the Alzheimer's brain. Cell Res 23: 595-596.

16. Adam-Vizi V, Allen TJ, Baker PF (1988) The effects of nitroprusside and putative agonists on guanylate cyclase activity in squid giant axons. Biochimica et Biophysica Acta 938: 461-468.

17. Ramon F, Moore JW (1978) Ephaptic transmission in squid giant axons. Am J Physiol 234: C162-C9.

18. Ramon F, Moore JW (1979) Propagation of action potentials in squid gian axons. Repetitive firing at regions of membrane in homogeneities. J Gen Physiol 73: 595-603.

19. Ramon F, Moore JW, Joyner RW, Westerfield M (1976) Squid giant axons. A model for the neuron soma? Biophysical Journal 16: 953-963

20. Stefano GB, Florey E (1991) Comparative aspects of neuropeptide function Manchester: University of Manchester Press.

21. Stefano GB, Catapane EJ, Aiello E (1976) Dopaminergic agents: Influence on serotonin in the molluscan nervous system. Science 194: 539-541.

22. Mantione KJ, Sheehan M, Gerber S, Kream RM, Zhu W, et al. (2009) Microarray Validation of Vertebrate Biogenic Amine and Acetylcholine Signaling in Invertebrates. Biogenic Amines 23: 135-44.

23. Stefano GB, Kream RM (1982) The calcium-dependent neuronal release of dopamine and its antagonism by lithium: Effects of lithium on opiate agonist and antagonist binding in the marine mollusc Mytilus edulis. In: Emrich HM, Aldenhoff JB, Lux HD, editors The calcium-dependent neuronal release of dopamine and its antagonism by lithium: Effects of lithium on opiate agonist and antagonist binding in the marine mollusc Mytilus edulis. Excerpta Medica Press 64-71.

24. Breton S, Stewart DT, Hoeh WR (2010) Characterization of a mitochondria ORF from the gender-associated mtDNAs of Mytilus spp. (Bivalvia: Mytilidae) identification of the "missing" ATPase 8 gene. Marine genomics 3: 11-18.

25. Stefano GB, Catapane EJ, Kream RM (1981) Characterization of the dopamine stimulated adenylate cyclase in the pedal ganglia of Mytilus edulis: Interactions with etorphine, b-endorphin, DALA and methionine enkephalin. Cell Mol Neurobiol 1: 57-68.

26. Doeller JE, Grieshaber MK, Kraus DW (2001) Chemolithoheterotrophy in a metazoan tissue: thiosulfate production matches ATP demand in ciliated mussel gills. J ExpBiol 204: 3755-64.

27. Stefano GB, Digenis A, Spector S, Leung MK, Bilfinger TV, et al. (1993) Opiatelike substances in an invertebrate, an opiate receptor on invertebrate and human immunocytes, and a role in immunosuppression. Proc Natl Acad Sci USA 90: 11099-11103

28. Stefano GB, Salzet M, Hughes TK, Shao L, Wang Y, et al. (1998) d2 opioid receptor subtype on human vascular endothelium uncouples morphine stimulated nitric oxide release. Int J Cardiol 64: S43-S51.

29. Salzet M, Stefano GB (2002) The endocannabinoid system in invertebrates. Prostaglandins Leukotrienes \& Essential Fatty Acids 66: 353-61.

30. Stefano GB, Salzet B, Fricchione GL (1998) Enkelytin and opioid peptide association in invertebrates and vertebrates: Immune activation and pain Immunol Today 19: 265-8.

31. Stefano GB, Salzet M (1999) Invertebrate opioid precursors: Evolutionary conservation and the significance of enzymatic processing. Int Rev Cytol 187 261-86.

32. Stefano GB (1989) Opioid peptides-comparative peripheral mechanisms. In Holmgren S, editor Opioid peptides-comparative peripheral mechanisms. New York: Chapman and Hall 112-29.

33. Stefano GB (1989) Role of opioid neuropeptides in immunoregulation. Prog Neurobiol 33: 149-59.

34. Stefano GB, Cadet P, Scharrer B (1989) Stimulatory effects of opioid neuropeptides on locomotory activity and conformational changes in invertebrate and human immunocytes: Evidence for a subtype of delta receptor. Proc Natl AcadSci USA 86: 6307-11.

35. Stefano GB, Janse C (1990) Molluscan models in aging studies in the centra 
Citation: Stefano GB, Kream RM (2015) Evolutionary Perspective on Microglial/Neuronal Coupling with Special Relevance to Psychiatric Illnesses. J Psychiatry 18: 329 doi:10.4172/2378-5756.1000329

Page 5 of 6

nervous system: Mytilus and Lymnaea. In: Stefano GB, editor Molluscan models in aging studies in the central nervous system: Mytilus and Lymnaea. Manchester, England: Manchester University Press 289-308

36. Stefano JM, Stefano GB (1990) Neural regulation of seasonality and rhythmicity in Mytilus edulis. In: Stefano GB, editor Neural regulation of seasonality and rhythmicity in Mytilus edulis. manchester: Manchester University Press 164-174.

37. Stefano GB (1990) Neurobiology of Mytilus edulis. Manchester: University of Manchester Press.

38. Stefano GB, Cadet P, Dokun A, Scharrer B (1990) A neuroimmunoregulatorylike mechanism responding to electrical shock in the marine bivalve Mytilus edulis. Brain Behavlmmun 4: 323-9.

39. Stefano GB (1990) Neurotransmitter/neuromodulator release mechanisms. In: Stefano GB, editor Neurotransmitter/neuromodulator release mechanisms. Manchester: Manchester University Press 120-37.

40. Stefano GB (1990) Norepinephrine: Presence and interaction with endogenous biogenic amines. In: Stefano GB, editor Norepinephrine: Presence and interaction with endogenous biogenic amines. Manchester: Manchester University Press 93-103.

41. Stefano GB (1990) Opioid receptor biochemistry in Mytilus edulis. In: Stefano GB, editor Opioid receptor biochemistry in Mytilus edulis. Manchester: Manchester University Press 138-147.

42. Stefano GB, Fricchione GL, Goumon Y, Esch T (2005) Pain, immunity, opiate and opioid compounds and health. Medical Science Monitor 11: MS47-MS53.

43. Hughes TK, Smith EM, Cadet P, Sinisterra JI, Leung MK, Shipp MA, et al. (1990) Interaction of immunoactive monokines (IL-1 and TNF) in the bivalve mollusc Mytilus edulis. Proc Natl Acad Sci USA 87: 4426-9.

44. Hughes TK, Smith EM, Stefano GB (1991) Detection of immunoreactive Interleukin-6 in invertebrate hemolymph and nervous tissue. Prog Neuroimmune Endocrinol 4: 234-9.

45. Stefano GB, Kream RM (2010) Dopamine, Morphine, and Nitric Oxide: An Evolutionary Signaling Triad. CNS Neuroscience \& Therapeutics 16: 124-e37.

46. Hughes TK, Jr, Smith EM, Barnett JA, Charles R, Stefano GB (1991) LPS stimulated invertebrate hemocytes: a role for immunoreactive TNF and IL-1. DevComplmmunol 15: 117-122.

47. Stefano GB, Smith DM, Smith EM, Hughes TK. (1991) MSH can deactivate both TNF stimulated and spontaneously active immunocytes. In: Kits KS, Boer HH, Joosse J, editors MSH can deactivate both TNF stimulated and spontaneously active immunocytes. Amsterdam: North Holland Publishing Company 206-9.

48. Stefano GB, Smith EM, Hughes TK (1991) Opioid induction of immunoreactive interleukin-1 in Mytilus edulis and human immunocytes: An interleukin-1-like substance in invertebrate neural tissue. J Neuroimmunol 32: 29-34.

49. Stefano GB, Scharrer B (1991) A possible immunoregulatory function for [Met]-enkephalin-Arg6-Phe7 involving human and invertebrate granulocytes. J Neuroimmunol 31: 97.

50. Smith EM, Hughes TK, Leung MK, Stefano GB (1991) The production and action of ACTH-related peptides in invertebrate hemocytes. AdvNeuroimmunol 1: 7-16.

51. Hughes TK, Chin R, Smith EM, Leung MK, Stefano GB (1991) Similarities of signal systems in vertebrates and invertebrates: Detection, action, and interactions of immunoreactive monokines in the mussel, Mytilus edulis. Adv Neuroimmunol 1: 59-70.

52. Mantione KJ, Kim C, Casares FM, Stefano GB (2012) Microarray validation of molecular and cellular signaling in Homarus americanus and Penaeus monodon. Invertebrate Survival Journal 9: 212-222.

53. Stefano GB, Sawada M, Smith EM, Hughes TK (1993) Selective effects of human immunodeficiency virus (HIV) gp120 on invertebrate neurons. Cell Mol Neurobiol 13: 569-577.

54. Mohankumar PS, Thyagarajan S, Quadri SK (1991) Interleukin-1 stimulates the release of dopamine and dihydroxyphenylacetic acid from the hypothalamus in vivo. Life Sci 48: 925-930.

55. Palazzolo DL, Quadri SK (1990) Interleukin-1 stimulates catecholamine release from the hypothalamus. Life Sci 47: 2105-2109.

56. Blalock JE, Smith EM (1985) A complete regulatory loop between the immune and neuroendocrine systems. Federation Proceedings 44: 101-111.

57. Blalock JE (1994) The immune system: our sixth sense. Immunologist 2: 8-15.

58. Blalock JE (1989) A molecular basis for bidirectional communication between the immune and neuroendocrine systems. Physiol Rev 69: 1-32.

59. Bilfinger TV, Fricchione GL, Stefano GB (1993) Neuroimmune implications of cardiopulmonary bypass. AdvNeuroimmunol 3: 277-288.

60. Stefano GB, Bilfinger TV, Fricchione GL (1994) The immune neuro-link and the macrophage: Postcardiotomy delirium, HIV-associated dementia and psychiatry. Prog Neurobiol 42: 475-88.

61. Morgese VJ, Elliott EJ, Muller KJ (1983) Microglial movement to sites of nerve lesions in the leech CNS. Brain Res 272: 166-70

62. Sonetti D, Ottaviani E, Bianchi F, Rodriquez M, Stefano ML, et al. (1994) Microglia in invertebrate ganglia. Proc Nat I Acad Sci USA 91: 9180-9184.

63. Sonetti D, Ottaviani E, Stefano GB (1997) Opiate signaling regulates microglia activities in the invertebrate nervous system. Gen Pharmacol 29: 39-47.

64. Peruzzi E, Fontana G, Sonetti D (2004) Presence and role of nitric oxide in the central nervous system of the freshwater snail Planorbarius corneus: possible implication in neuron-microglia communication. Brain Res 1005: 9-20.

65. Stefano GB, Teoh MB, Grant A, Reid C, Teoh H, et al. (1994) Electric field exposure activates immunocytes: Evidence for calcium dependency. ElectroMagnetobiol 13: 123-36.

66. Stefano GB (1992) Invertebrate and vertebrate immune and nervous system signal molecule commonalities. Cell Mol Neurobiol 12: 357-66.

67. Beck G, O'Brien RF, Habicht GS, Stillman DL, Cooper EL, et al. (1993) Invertebrate cytokines. III: Invertebrate interleukin-1-like molecules stimulate phagocytosis by tunicate and echinoderm cells. Cellular Immunology 146: 284-99.

68. Dobrenis K, Makman MH, Stefano GB (1995) Occurrence of the opiate alkaloid-selective $\mathrm{m} 3$ receptor in mammalian microglia, astrocytes and kupffe cells. Brain Res 686: 239-48.

69. Makman MH, Bilfinger TV, Stefano GB (1995) Human granulocytes contain an opiate receptor mediating inhibition of cytokine-induced activation and chemotaxis. J Immunol 154: 1323-30.

70. Scharrer B, Paemen LR, Smith EM, Hughes TK, Liu Y, et al. (1996) The presence and effects of mammalian signal molecules in immunocytes of the insect Leucophaea madarae. Cell Tiss Res 283: 93-97.

71. Cadet P, Mantione KJ, Zhu W, Kream RM, Sheehan M, et al. (2007) A functionally coupled mu3-like opiate receptor/nitric oxide regulatory pathway in human multi-lineage progenitor cells. J Immunol 179: 5839-5844.

72. Gerber S, Cadet P, Sheehan M, Stefano GB, Mantione KJ (2007) Vertebrate interleukins originated in invertebrates? Invertebrate Survival Journal 4: 95-100.

73. Stefano GB, Cadet P, Kream RM, Zhu W (2008) The presence of endogenous morphine signaling in animals. Neurochemical Research 33: 1933-1939.

74. Stefano GB, Kim E, Liu Y, Zhu W, Casares F, Mantione K, et al. (2004) Nitric oxide modulates microglial activation. Med Sci Monit 10: BR17-BR22.

75. Stefano GB, Leung MK, Zhao XH, Scharrer B (1989) Evidence for the involvement of opioid neuropeptides in the adherence and migration of immune competent invertebrate hemocytes. Proc Natl Acad Sci USA 86: 626-30.

76. Sawada M, Hara N, Maeno T (1991) lonic mechanism of the outward current induced by extracellular ejection of interleukin-1 onto identified neurons of Aplysia. Brain Res 545: 248-256.

77. Szucs A, Stefano GB, Hughes TK, Rozsa KS (1992) Modulation of voltageactivated ion currents on identified neurons of Helix pomatia L. by interleukin-1. Cell Mol Neurobiol 12: 429-438.

78. Mantione KJ, Kream RM, Kuzelova H, Ptacek R, Raboch J, Samuel JM, et al. (2014) Comparing bioinformatic gene expression profiling methods: Microarray and RNA-Seq. Med Sci Monit Basic Res 20: 138-41.

79. Stefano GB (1988) The evolvement of signal systems: conformational matching a determining force stabilizing families of signal molecules. Comp Biochem Physiol C 90: 287-94.

80. Snyder C, Stefano GB (2015) Mitochondria and Chloroplasts Shared in Anima and Plant Tissues: Significance of Communication. Med Sci Monit 21: 1507-11. 
Citation: Stefano GB, Kream RM (2015) Evolutionary Perspective on Microglial/Neuronal Coupling with Special Relevance to Psychiatric Illnesses. J Psychiatry 18: 329 doi:10.4172/2378-5756.1000329

81. Stefano GB, Snyder C, Kream RM (2015) Mitochondria, Chloroplasts in Animal and Plant Cells: Significance of Conformational Matching. Med Sci Monit 21REV 2064-9.

82. Stefano GB (1986) Conformational matching: a possible evolutionary force in the evolvement of signal systems. In: Stefano GB, editor Conformational matching: a possible evolutionary force in the evolvement of signal systems. Boca Raton: CRC Press Inc 271-7.

83. Stefano GB (1991) Conformational matching: a stabilizing signal system facto during evolution: Additional evidence in comparative neuroimmunology. Adv Neuroimmunol 1: 71-82.

84. Stefano GB (1991) Stereo specificity as a determining force stabilizing families of signal molecules within the context of evolution. In: Stefano GB Florey $\mathrm{E}$, editors Stereospecificity as a determining force stabilizing families of signal molecules within the context of evolution. Manchester: University of Manchester Press 14-28.

85. Stefano GB, Scharrer B (1994) Endogenous morphine and related opiates, a new class of chemical messengers. Adv Neuroimmunol 4: 57-68.

86. Kream RM, Stefano GB (2006) De novo biosynthesis of morphine in anima cells: An evidence-based model. Medical Science Monitor 12: RA207-RA19.

87. Tasiemski A, Verger-Bocquet $M$, Cadet M, Goumon $\mathrm{Y}$, Metz-Boutigue $\mathrm{MH}$, et al. (2000) Proenkephalin A-derived peptides in invertebrate innate immune processes. Brain Res Mol Brain Res 76: 237-252.

88. Wang F, Stefano GB, Kream RM (2014) Epigenetic modification of DRG neuronal gene expression subsequent to nerve injury: Etiological contribution to complex regional pain syndromes (Part I). Med Sci Monit 20: 1067-1077.

89. Wang F, Stefano GB, Kream RM (2014) Epigenetic modification of DRG neuronal gene expression subsequent to nerve injury: Etiological contribution to Complex Regional Pain Syndromes (Part II). Med Sci Monit 20: 1188-1200.

90. Wang F, Guo X, Shen X, Kream RM, Mantione KJ, et al. (2014) Vascular Dysfunction Associated with Type II Diabetes and Alzheimer's Disease: A Potential Etiological Linkage. Med Sci Monit Basic Res 20: 118-129.

91. Stefano GB, Kream RM (2015) Hypoxia Defined as a Common Culprit/Initiation Factor in Mitochondrial-Mediated Proinflammatory Processes. Med Sci Monit 21: $1478-1484$.

92. Stefano GB, Kream RM (2015) Nitric Oxide Regulation of Mitochondrial Processes: Commonality in Medical Disorders. Annals of Transplantation 20: 402-7.

93. Stefano GB, Kream R (2015) Psychiatric Disorders Involving Mitochondrial Processes. Psychology Observer 1: 1-6. 